widely acclaimed as a useful resource for all those working in the End of Life Care field. Commissioners and providers are actively using the website to inform changes in care at a local level. National outputs are informing the development of National Policy.

There is no other web-based resource which is similar. It provides a completely new approach to accessing National and Local information. The website and its functionality will be demonstrated to show how its use can advance knowledge and understanding of the quality of End of Life Care.

\title{
52 INTRODUCTION TO THE NATIONAL (ENGLAND) END OF LIFE CARE INTELLIGENCE NETWORK WEBSITE
}

\author{
10.1136/bmjspcare-2011-000053.52
}

J Verne South West Public Health Observatory, Bristol, UK

The National End of Life Care Intelligence Network and its website were launched in June 2010. It is a national resource for policy makers and planners and providers of End of Life care as well as researchers, media and the public. The aim is to bring together in one easily accessible place evidence on End of Life Care particularly using data sources. The website (http://www.endoflifecare-intelligence.org.uk/home. aspx) has several domains: Local profiles by Local Authority (numbers and rates of deaths by major cause, age and place of death); Reports (Deaths In Older Adults in England; Variations In Place of Death in England; Deaths Registered as Occurring 'Elsewhere'; External Causes of Death); A compendium of data sources; Advice and information - signposting for patients, their relatives and carers; Email alerts - sign up to receive regular information; News and events - keep up-to-date with developments. It is planned to expand the functionality by links with academic partners to bring more of the research evidence together with the routine data analyses. The concept is new and innovative and has already been 